\title{
Selenoprotein expression and brain development in preweanling selenium- and iodine-deficient rats
}

\section{J H Mitchell, F Nicol, G J Beckett ${ }^{1}$ and J R Arthur}

Division of Biochemical Sciences, Rowett Research Institute, Greenburn Road, Bucksburn, Aberdeen AB21 9SB, UK

${ }^{1}$ University Department of Clinical Biochemistry, The Royal Infirmary, Edinburgh EH3 9YW, UK

(Requests for offprints should be addressed to J R Arthur)

\begin{abstract}
Selenium deficiency causes further impairment of thyroid hormone metabolism in iodine-deficient rats and therefore could have a role in the aetiology of both myxoedematous and neurological cretinism in humans. Thyroidal type I iodothyronine deiodinase (ID-I), cytosolic glutathione peroxidase and phospholipid hydroperoxide glutathione peroxidase activities were increased in iodine-deficient adult rats and their offspring at 11 days of age. Thyroidal ID-I activity was unchanged and thyroidal cytosolic glutathione peroxidase activity was decreased by more than $75 \%$ by combined selenium and iodine deficiency in 11-day-old rats, indicating that, while the thyroid retained an ability to produce $3,3^{\prime}, 5$-triiodothyronine $\left(\mathrm{T}_{3}\right)$, the gland was probably more susceptible to peroxidative damage caused by increased hydrogen peroxide concentrations driven by increased thyrotrophin. Thyroidal atrophy, common in myxoedematous cretinism, did not occur in iodine- or selenium and iodine-deficient rat
\end{abstract}

pups. Iodine deficiency increased brain type II iodothyronine deiodinase activity $1 \cdot 5$-fold in 4 -dayold rats and 3-fold in 11-day-old rats, regardless of selenium status. Thus rats were able to activate compensatory mechanisms in brain that would maintain $\mathrm{T}_{3}$ concentrations in selenium and iodine deficiencies. Surprisingly, however, selenium deficiency had a greater effect than iodine deficiency on markers of brain development in rat pups. Expression of the brain-derived neurotrophic factor (BDNF) mRNA was decreased in selenium deficiency in 4- and 11-day-old pups and in combined selenium and iodine deficiency in 4-day-old pups. Iodine deficiency caused an increase in BDNF expression in 11-day-old pups but had no effect on 4-day-old pups. Myelin basic protein mRNA expression in brain was decreased by combined selenium and iodine deficiency in 11-day-old rats. Fournal of Molecular Endocrinology (1998) 20, 203-210

\section{INTRODUCTION}

Selenium and iodine are both essential for thyroid hormone metabolism and thus play a vital role in the health of man and animals. Iodine is an essential substrate for thyroid hormone synthesis, whilst selenium is required for the expression of the selenoenzymes type I iodothyronine deiodinase (ID-I) and type II iodothyronine deiodinase (ID-II), which are crucial in the generation of the active hormone 3,3',5-tri-iodothyronine $\left(\mathrm{T}_{3}\right)$ (Arthur et al. 1990a, Croteau et al. 1995). A consequence of selenium deficiency is that conversion of thyroxine $\left(\mathrm{T}_{4}\right)$ to $\mathrm{T}_{3}$ by hepatic and renal ID-I is decreased by over $90 \%$. In contrast, thyroidal ID-I activity is increased in acute selenium deficiency which helps maintain plasma
$\mathrm{T}_{3}$ concentrations (Beckett et al. 1993). Further compensatory mechanisms in selenium deficiency include no change in brain ID-II activity in rats until very severe deficiency is induced. This allows maintenance of $\mathrm{T}_{3}$ concentrations within the central nervous system, which cannot utilise circulating $\mathrm{T}_{3}$ (Beckett et al. 1993, Mitchell et al. 1996).

Mammals depend on thyroid hormones for normal growth and development, with nuclear $\mathrm{T}_{3}$ receptors detected in foetal rat brain by 13 days of gestation (Perez-Castillo et al. 1985). In iodine deficiency, a number of mechanisms are evoked to maintain thyroid hormone synthesis. Such mechanisms also increase the requirement for selenoproteins in the thyroid gland (Mitchell et al. 1996). Selenium deficiency may therefore aggravate the damaging effects of iodine deficiency in man and 
animals by increasing the hypothyroid stress on the thyroid gland (Beckett et al. 1993, Contempre et al. 1995). In contrast, selenium deficiency can provide partial protection against the lowering of plasma thyroxine $\left(\mathrm{T}_{4}\right)$ concentrations in humans, which may help to prevent foetal brain damage and neurological cretinism (Contempre et al. 1991, 1992).

Evidence would thus suggest that concurrent selenium deficiency in adult iodine-deficient rats causes a greater oxidant stress on the thyroid gland than iodine deficiency alone, yet sufficient selenium is 'channelled' towards the thyroid gland to try to maintain the thyroidal selenoprotein activity (Beckett et al. 1993, Mitchell et al. 1996). Consequently, we examined the effects of concurrent selenium and iodine deficiencies on adult rats and their offspring at different postnatal ages to determine development of the ability of preweanling rats to retain thyroid hormone metabolism and function. We also assessed brain developmental biochemistry of pups of selenium- and iodine-deficient rats by the expression of the brain-derived nerve growth factor (BDNF) (Leibrock et al. 1989) and the myelination marker, myelin basic protein (MBP) (Kristensson et al. 1986).

\section{MATERIALS AND METHODS}

\section{Chemicals}

Unless otherwise stated, chemicals were purchased from Sigma Chemical Company, Poole, Dorset, UK. Multiprime labelling kits, Hyperfilm-MP and $\left[{ }^{32} \mathrm{P}\right] \mathrm{dCTP}$ for mRNA determination along with ${ }^{125}$ I-labelled reverse $T_{3}$ for deiodinase determination were purchased from Amersham International, Amersham, Bucks, UK.

\section{Animals and diets}

Groups of three female Hooded Lister weanling rats of the Rowett Institute strain were fed on one of the four diets: (1) selenium- and iodine-adequate control (+Se+I), (2) selenium-deficient iodineadequate $(-\mathrm{Se}),(3)$ iodine-deficient seleniumadequate $(-\mathrm{I})$, (4) selenium- and iodine-deficient ( $-\mathrm{Se}-\mathrm{I}$ ) (Mitchell et al. 1996). After 8 weeks the rats were mated with normal males. At the end of the experiment, rats were anaesthetised with isoflurane and blood collected by cardiac puncture from adult and 11-day-old rats. Pups from each mother were killed on postnatal days 1, 4 and 11 . Blood from 11-day-old animals was pooled in each litter to allow sufficient sample to harvest plasma. Liver, thyroid and brain were removed, immediately frozen in liquid nitrogen and stored at $-70{ }^{\circ} \mathrm{C}$ before analysis.

\section{Enzyme activities and thyroid hormone concentrations}

ID-I and ID-II activities were determined using ${ }^{125} \mathrm{I}$-labelled reverse $\mathrm{T}_{3}$ as substrate (Nicol et al. 1994). Cytosolic glutathione peroxidase ( $c$ GSHPx) activity was measured by the method described by Beckett et al. (1987) and phospholipid hydroperoxide glutathione peroxidase ( $p h \mathrm{GSHPx}$ ) activity by the method of Weitzel et al. (1990). Plasma thyrotrophin-stimulating hormone ( $\mathrm{TSH}$ ), $\mathrm{T}_{4}$ and $\mathrm{T}_{3}$ concentrations were determined as described by Arthur et al. (1990b).

\section{Northern blot hybridisation}

Total RNA was extracted from tissues (Chomczynski \& Sacchi 1987) and $20 \mu \mathrm{g}$ aliquots of mRNA separated by electrophoresis on a $1 \cdot 2 \%$ denaturing agarose gel. The separated RNA was transferred to nylon membrane by capillary blotting and fixed using UV-light-induced crosslinking. cDNA probes for ID-I, $c$ GSHPx, phGSHPx and 18S rRNA were as described previously (Mitchell et al. 1996). The $2.21 \mathrm{~kb}$ MBP cDNA was kindly provided by Dr Robert Lazzarini, The Mount Sinai School of Medicine (Kristensson et al. 1986). The partial BDNF clone was provided by $\mathrm{Dr}$ Lisa Monteggia, Abbott Laboratories, IL, USA (Giordano et al. 1992). Hybridisation was performed as described previously (Mitchell et al. 1996). mRNA was quantified using a Packard Instantimager and by autoradiography against Hyperfilm-MP at $-70{ }^{\circ} \mathrm{C}$. After use of each cDNA probe, membranes were washed in $0 \cdot 1 \%$ SDS at $95^{\circ} \mathrm{C}$ for $10 \mathrm{~min}$ to remove the label before rehybridisation. mRNA levels are given as ${ }^{32} \mathrm{P}$ counts corrected for hybridisation with $18 \mathrm{~S}$ rRNA to correct for any variation in loading or transfer to the membrane. Results for each filter were expressed as a percentage of the mean for animals fed on the control diet $(+\mathrm{Se}+\mathrm{I})$.

\section{Statistical analysis}

Group means were compared by ANOVA using the 'Genstat Statistics Package' (Genstat 5 Committee, Genstat 5 release3, reference manual 1993, Clarendon, Oxford, UK). 
TABLE 1. Effects of selenium and iodine deficiencies on body and thyroid gland weights and plasma thyroid hormone concentrations. Data are means \pm s.E.M (adults $n=3$, pups $n=5$ )

\begin{tabular}{|c|c|c|c|c|}
\hline & $+\mathrm{Se}+\mathrm{I}$ & $-\mathrm{Se}$ & $-\mathbf{I}$ & $-\mathbf{S e}-\mathbf{I}$ \\
\hline \multicolumn{5}{|l|}{ Body weight (g) } \\
\hline Adult-mating & $206 \pm 8 \cdot 30$ & $187 \pm 5 \cdot 60$ & $191 \pm 5 \cdot 13$ & $186 \pm 5 \cdot 52$ \\
\hline Adult-final & $249 \pm 2 \cdot 60$ & $226 \pm 4 \cdot 51 *$ & $222 \pm 6 \cdot 68 * *$ & $218 \pm 6 \cdot 84 * *$ \\
\hline 11-day-old & $22 \cdot 5 \pm 2 \cdot 30$ & $23 \cdot 0 \pm 0 \cdot 76$ & $19 \cdot 2 \pm 0 \cdot 35$ & $20 \cdot 3 \pm 1 \cdot 05$ \\
\hline 4-day-old & $7 \cdot 83 \pm 0 \cdot 66$ & $8 \cdot 62 \pm 0 \cdot 45$ & $7 \cdot 84 \pm 0 \cdot 34$ & $7 \cdot 41 \pm 0 \cdot 28$ \\
\hline 1-day-old & $5 \cdot 75 \pm 0 \cdot 72$ & $4 \cdot 95 \pm 0.53$ & $4 \cdot 79 \pm 0 \cdot 25 *$ & $4 \cdot 07 \pm 0 \cdot 43^{* * * *}$ \\
\hline Average pups/dam & 8 & 8 & 9 & 7 \\
\hline \multicolumn{5}{|c|}{ Thyroid weight ( $\%$ body weight) } \\
\hline Adult & $0 \cdot 011 \pm 0 \cdot 001$ & $0 \cdot 012 \pm 0 \cdot 001$ & $0.063 \pm 0.005^{* * *}$ & $0.073 \pm 0.008 * * *$ \\
\hline 11-day-old & $0.022 \pm 0.003$ & $0 \cdot 019 \pm 0 \cdot 001$ & $0.055 \pm 0.008^{* * *}$ & $0 \cdot 056 \pm 0 \cdot 005^{* * * *}$ \\
\hline \multicolumn{5}{|l|}{ Plasma $\mathbf{T}_{4}(\mathrm{nmol} / \mathrm{l})$} \\
\hline Adult & $39 \cdot 0 \pm 6 \cdot 08$ & $48 \cdot 3 \pm 4 \cdot 33$ & $5 \cdot 75 \pm 1 \cdot 32 * * *$ & $7 \cdot 67 \pm 0 \cdot 33^{* * * *}$ \\
\hline 11-day-old & $51 \cdot 3 \pm 2 \cdot 73$ & $66 \cdot 7 \pm 2 \cdot 85^{* * *}$ & $10 \cdot 3 \pm 1 \cdot 38^{* * * *}$ & $9 \cdot 7 \pm 0 \cdot 5^{* * *}$ \\
\hline \multicolumn{5}{|l|}{ Plasma $_{\mathbf{T}_{3}}(\mathrm{nmol} / \mathrm{l})$} \\
\hline Adult & $0 \cdot 46 \pm 0 \cdot 012$ & $0 \cdot 51 \pm 0 \cdot 062$ & $0 \cdot 24 \pm 0 \cdot 060 * * *$ & $0 \cdot 41 \pm 0 \cdot 078$ \\
\hline 11-day-old & $0 \cdot 83 \pm 0 \cdot 13$ & $0 \cdot 73 \pm 0 \cdot 035$ & $0 \cdot 62 \pm 0 \cdot 06^{*}$ & $0 \cdot 58 \pm 0 \cdot 10^{*}$ \\
\hline \multicolumn{5}{|l|}{ Plasma TSH (ng/ml) } \\
\hline Adult & $1 \cdot 94 \pm 0 \cdot 43$ & $4 \cdot 04 \pm 0 \cdot 20 *$ & $51 \cdot 1 \pm 4 \cdot 23^{* * *}$ & $58 \cdot 6 \pm 6 \cdot 04 * * *$ \\
\hline 11-day-old & $3 \cdot 67 \pm 0 \cdot 24$ & $4 \cdot 01 \pm 0 \cdot 39$ & $21 \cdot 82 \pm 2 \cdot 89^{* * * *}$ & $14 \cdot 19 \pm 0 \cdot 67 * * *$ \\
\hline
\end{tabular}

Thyroid gland weights are expressed as percentage of total body weight. * $P<0 \cdot 05$, *** $P<0 \cdot 01$, *** $P<0 \cdot 001$ as compared with control group ( $+\mathrm{Se}+\mathrm{I}$ ) (ANOVA).

\section{RESULTS}

\section{Rat body and thyroid weights}

There were no significant differences between the groups of female rats with respect to food intake (not shown), weight at mating or average number of pups born (Table 1). However, both selenium and iodine deficiencies caused decreases in body weight of the female rats at the end of the experiment. Pups from iodine-deficient females were of lower body weight than controls at 1 day old but there was no effect of selenium or iodine deficiencies on body weights of 4- or 11-day-old pups (Table 1). Selenium deficiency had no effect on thyroid weight in adult rats or their 11-day-old pups (expressed as percentage of body weight). Iodine deficiency caused 7 -fold and 2.5-fold increases in thyroid weight in adult rats and their 11-day-old pups, regardless of selenium status (Table 1 ).

\section{Plasma thyroid hormone concentrations}

In selenium deficiency, plasma $\mathrm{T}_{4}$ concentrations were unchanged in adults but increased significantly in 11-day-old pups (Table 1). Iodine deficiency caused decreases in plasma $\mathrm{T}_{4}$ concentrations to $<20 \%$ of control $(+\mathrm{Se}+\mathrm{I})$ in adult and 11-day-old pups, regardless of selenium status. Plasma $\mathrm{T}_{3}$ concentrations were unaffected by selenium deficiency but were decreased by iodine deficiency in adult and 11-day-old pups. Combined selenium and iodine deficiency decreased plasma $\mathrm{T}_{3}$ concentrations in 11-day-old rats but had no effect in adult rats. Iodine deficiency caused 25-fold and 5-fold increases in plasma TSH concentration in adult rats and their 11-day-old pups, regardless of selenium status. Plasma TSH concentrations were increased by selenium deficiency in adult rats but were unchanged in 11-day-old pups.

\section{Thyroid selenoenzyme activities}

In adult rats, thyroid ID-I activity (per mg protein) was increased in selenium deficiency, decreased in iodine deficiency and unchanged in combined selenium and iodine deficiency (Table 2). However, total ID-I activity per gland was increased 2-fold in both iodine-deficient groups and unchanged in selenium deficiency (Fig. 1). ID-I activity in thyroid glands from 11-day-old rats (per gland and per mg protein) was decreased by selenium deficiency, increased by iodine deficiency and unchanged by combined selenium and iodine deficiency (Fig. 1 and Table 2). In adult rats, thyroidal $c$ GSHPx and 
TABLE 2. Hepatic and thyroidal selenoenzyme activities in adult rats and their offspring at 1,4 and 11 days of age. Group means \pm s.E.M. are shown (adults $n=3$, pups $n=5$ )

\begin{tabular}{|c|c|c|c|c|}
\hline \multirow{3}{*}{ Adult thyroi } & \multicolumn{4}{|c|}{ Enzyme activity } \\
\hline & \multirow[t]{2}{*}{$+\mathrm{Se}+\mathrm{I}$} & \multirow[t]{2}{*}{$-\mathrm{Se}$} & \multirow[t]{2}{*}{$-\mathrm{I}$} & \multirow[t]{2}{*}{$-\mathrm{Se}-\mathrm{I}$} \\
\hline & & & & \\
\hline ID-I & $65 \cdot 1 \pm 9 \cdot 02$ & $83 \cdot 2 \pm 2 \cdot 77$ *** & $51 \cdot 9 \pm 2 \cdot 89^{*}$ & $58 \cdot 4 \pm 8 \cdot 46$ \\
\hline$c \mathrm{GSHPx}$ & $0 \cdot 12 \pm 0 \cdot 01$ & $0 \cdot 08 \pm 0 \cdot 01 * *$ & $0 \cdot 24 \pm 0 \cdot 02 * * *$ & $0 \cdot 15 \pm 0 \cdot 02$ \\
\hline$p h \mathrm{GSHPx}$ & $3 \cdot 07 \pm 0 \cdot 16$ & $2 \cdot 30 \pm 0 \cdot 60 *$ & $3 \cdot 66 \pm 0 \cdot 14 *$ & $3 \cdot 17 \pm 0 \cdot 19$ \\
\hline \multicolumn{5}{|c|}{ 11-Day thyroid } \\
\hline ID-I & $29 \cdot 7 \pm 8 \cdot 29$ & $11 \cdot 4 \pm 0 \cdot 70^{* * * *}$ & $69 \cdot 4 \pm 9 \cdot 62 * * * *$ & $30 \cdot 8 \pm 4 \cdot 84$ \\
\hline$c$ GSHPx & $0 \cdot 05 \pm 0 \cdot 01$ & $0 \cdot 012 \pm 0 \cdot 01 * * * *$ & $0 \cdot 08 \pm 0 \cdot 01^{*}$ & $0 \cdot 02 \pm 0 \cdot 01 * * *$ \\
\hline phGSHPx & $1 \cdot 30 \pm 0 \cdot 20$ & $0 \cdot 80 \pm 0 \cdot 02 * *$ & $1 \cdot 63 \pm 0 \cdot 18$ & $1 \cdot 40 \pm 0 \cdot 15$ \\
\hline \multicolumn{5}{|l|}{ Adult liver } \\
\hline ID-I & $26 \cdot 1 \pm 1 \cdot 92$ & $2 \cdot 43 \pm 0 \cdot 49 * * *$ & $4 \cdot 8 \pm 0 \cdot 43 * * * *$ & $1 \cdot 6 \pm 0 \cdot 44 * * *$ \\
\hline$c \mathrm{GSHPx}$ & $0 \cdot 89 \pm 0 \cdot 04$ & $0 \cdot 018 \pm 0 \cdot 01 * * *$ & $0 \cdot 77 \pm 0 \cdot 070$ & $0.022 \pm 0.002 * * *$ \\
\hline$p h \mathrm{GSHPx}$ & $1 \cdot 01 \pm 0 \cdot 20$ & $0 \cdot 51 \pm 0 \cdot 16^{*}$ & $1 \cdot 16 \pm 0 \cdot 16$ & $0 \cdot 32 \pm 0 \cdot 17 * * *$ \\
\hline \multicolumn{5}{|l|}{ 11-Day liver } \\
\hline ID-I & $26 \cdot 6 \pm 2 \cdot 54$ & $1 \cdot 5 \pm 0 \cdot 40 * * *$ & $16 \cdot 4 \pm 1 \cdot 01 * *$ & $0 \cdot 98 \pm 0 \cdot 14 * * *$ \\
\hline$c \mathrm{GSHPx}$ & $0 \cdot 16 \pm 0 \cdot 021$ & $0 \cdot 01 \pm 0 \cdot 001 * * *$ & $0 \cdot 18 \pm 0 \cdot 034$ & $0 \cdot 01 \pm 0 \cdot 001 * * * *$ \\
\hline$p h \mathrm{GSHPx}$ & $1 \cdot 15 \pm 0 \cdot 40$ & $0 \cdot 27 \pm 0 \cdot 06^{* * *}$ & $0.46 \pm 0.07 * *$ & $0 \cdot 43 \pm 0 \cdot 12 * *$ \\
\hline \multicolumn{5}{|l|}{ 4-Day liver } \\
\hline ID-I & $17 \cdot 5 \pm 2 \cdot 69$ & $1 \cdot 5 \pm 0 \cdot 22 * * *$ & $11 \cdot 3 \pm 0 \cdot 89^{*}$ & $1 \cdot 7 \pm 0 \cdot 44 * * *$ \\
\hline$c \mathrm{GSHPx}$ & $0 \cdot 12 \pm 0 \cdot 005$ & $0 \cdot 01 \pm 0 \cdot 001 * * * *$ & $0 \cdot 13 \pm 0 \cdot 018$ & $0 \cdot 01 \pm 0 \cdot 001 * * *$ \\
\hline$p h \mathrm{GSHPx}$ & $0 \cdot 71 \pm 0 \cdot 17$ & $0 \cdot 39 \pm 0 \cdot 19^{*}$ & $0 \cdot 69 \pm 0 \cdot 17$ & $0 \cdot 15 \pm 0 \cdot 04^{* * * *}$ \\
\hline \multicolumn{5}{|l|}{ 1-Day liver } \\
\hline ID-I & $13 \cdot 9 \pm 2 \cdot 11$ & $1 \cdot 4 \pm 0 \cdot 38 * * *$ & $13 \cdot 1 \pm 1 \cdot 15$ & $1 \cdot 5 \pm 0 \cdot 44 * * *$ \\
\hline$c \mathrm{GSHPx}$ & $0 \cdot 19 \pm 0 \cdot 021$ & $0.01 \pm 0.001 * * *$ & $0 \cdot 15 \pm 0 \cdot 018$ & $0.01 \pm 0.001 * * *$ \\
\hline phGSHPx & $2 \cdot 08 \pm 0 \cdot 52$ & $1 \cdot 10 \pm 0 \cdot 46^{*}$ & $1 \cdot 41 \pm 0 \cdot 23^{*}$ & $1 \cdot 26 \pm 0 \cdot 35^{*}$ \\
\hline
\end{tabular}

ID-I activity is expressed as pmol I released/min per mg protein. $c$ GSHPx activity is expressed as units $/ \mathrm{mg}$ protein and $p h \mathrm{GSPHx}$ activity is expressed as munits $/ \mathrm{mg}$ protein.

${ }^{*} P<0 \cdot 05$, ** $P<0 \cdot 01$, **** $P<0 \cdot 001$ as compared with control ( $+\mathrm{Se}+\mathrm{I}$ ) (ANOVA).

phGSHPx activities were decreased by selenium deficiency, increased by iodine deficiency and unchanged in combined selenium and iodine deficiency in adult rats (Table 2). cGSHPx activity in thyroids of 11-day-old rats was increased in iodine deficiency and decreased in both seleniumdeficient groups. Thyroidal phGSHPx activity in 11-day-old rats was decreased in selenium deficiency but unchanged in both iodine-deficient groups.

\section{Hepatic selenoenzyme activities}

Selenium deficiency, regardless of iodine status, decreased hepatic ID-I activity to less than $10 \%$ of control $(+\mathrm{Se}+\mathrm{I})$ in adult rats and their offspring at 1,4 and 11 days (Table 2). Iodine deficiency decreased hepatic ID-I activity in adult, 11-dayand 4-day-old rats but had no effect on ID-I activity in livers from 1-day-old rats. Selenium deficiency

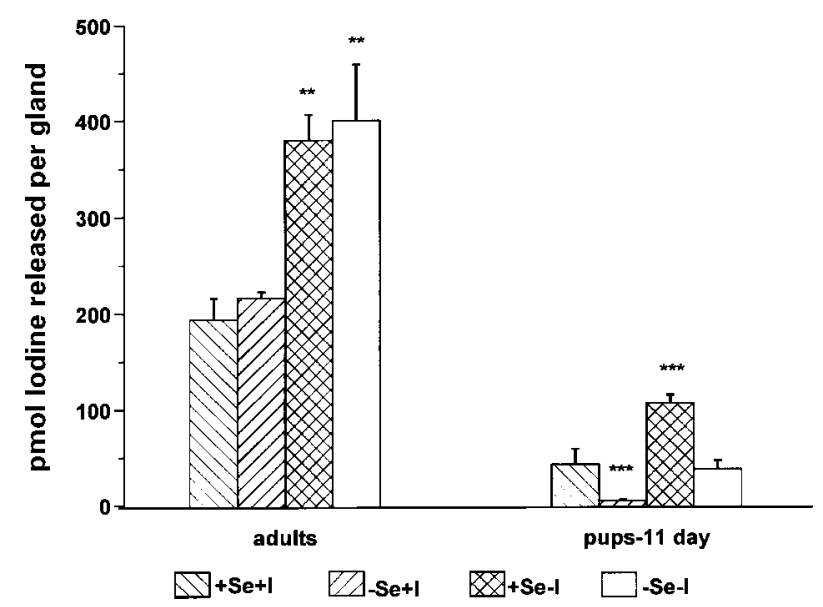

FIGURE 1. ID-I activities in thyroid glands from adult and 11-day-old rats. ID-I activity is expressed as pmol iodine released/gland. Means \pm S.E.M. are shown (adults $n=3$, pups $n=5)$. ** $P<0 \cdot 01$, *** $P<0 \cdot 001$ as compared with control $(+\mathrm{Se}+\mathrm{I})(\mathrm{ANOVA})$. 
TABLE 3. Selenoperoxidase activity and mRNA abundance in cerebrum from 1 -, 4- and 11-day-old rats, expressed as \% control where control value $=100 \%$. Mean \pm s.E.M. are shown. $(n=5 /$ group)

\begin{tabular}{|c|c|c|c|c|}
\hline & $+\mathrm{Se}+\mathrm{I}$ & $-\mathbf{S e}$ & $-\mathbf{I}$ & $-\mathbf{S e}-\mathbf{I}$ \\
\hline \multicolumn{5}{|l|}{ 11-Day-old } \\
\hline$c$ GSHPx activity & $100 \pm 4 \cdot 5$ & $51 \cdot 9 \pm 3 \cdot 5 * *$ & $89 \cdot 1 \pm 7 \cdot 9$ & $56 \cdot 7 \pm 5 \cdot 9 * *$ \\
\hline$c$ GSHPx mRNA & $100 \pm 8 \cdot 7$ & $156 \pm 13 \cdot 0 * *$ & $139 \pm 8 \cdot 7 *$ & $148 \pm 21 \cdot 7 *$ \\
\hline$p h \mathrm{GSHPx}$ activity & $100 \pm 8 \cdot 9$ & $107 \pm 18 \cdot 5$ & $97 \cdot 4 \pm 10 \cdot 5$ & $89 \cdot 9 \pm 8 \cdot 1$ \\
\hline$p h \mathrm{GSHPx}$ mRNA & $100 \pm 3 \cdot 8$ & $169 \pm 15 \cdot 3 * * *$ & $130 \pm 3 \cdot 8 * *$ & $119 \pm 11 \cdot 5 *$ \\
\hline \multicolumn{5}{|l|}{ 4-Day-old } \\
\hline$c$ GSHPx activity & $100 \pm 4 \cdot 8$ & $52 \cdot 1 \pm 6 \cdot 9 * *$ & $92 \cdot 0 \pm 2 \cdot 9$ & $59 \cdot 2 \pm 4 \cdot 4 * *$ \\
\hline$c$ GSHPx mRNA & $100 \pm 17 \cdot 0$ & $61 \cdot 7 \pm 4 \cdot 3 *$ & $79 \cdot 6 \pm 6 \cdot 4$ & $70 \cdot 2 \pm 8 \cdot 5^{*}$ \\
\hline phGSHPx activity & $100 \pm 7 \cdot 9$ & $94 \cdot 8 \pm 1 \cdot 9$ & $102 \pm 7 \cdot 7$ & $107 \pm 7 \cdot 8$ \\
\hline$p h \mathrm{GSHPx} \mathrm{mRNA}$ & $100 \pm 10 \cdot 8$ & $132 \pm 8 \cdot 1 * *$ & $100 \pm 8 \cdot 1$ & $124 \pm 10 \cdot 8 *$ \\
\hline \multicolumn{5}{|l|}{ 1-Day-old } \\
\hline$c$ GSHPx activity & $100 \pm 7 \cdot 3$ & $41 \cdot 2 \pm 3 \cdot 1 * * * *$ & $72 \cdot 6 \pm 3 \cdot 1 *$ & $48 \cdot 4 \pm 5 \cdot 3 * *$ \\
\hline$c$ GSHPx mRNA & $100 \pm 8 \cdot 5$ & $74 \cdot 8 \pm 9 \cdot 4^{*}$ & $63 \cdot 5 \pm 9 \cdot 8^{*}$ & $74 \cdot 2 \pm 7 \cdot 0^{*}$ \\
\hline$p h$ GSHPx activity & $100 \pm 38 \cdot 3$ & $104 \pm 14 \cdot 6$ & $127 \pm 18 \cdot 1$ & $107 \pm 9 \cdot 9$ \\
\hline$p h \mathrm{GSHPx} \mathrm{mRNA}$ & $100 \pm 13 \cdot 2$ & $127 \pm 4 \cdot 1$ & $60 \cdot 2 \pm 10 \cdot 2^{* * *}$ & $105 \pm 18 \cdot 4$ \\
\hline
\end{tabular}

$c$ GSHPx activity is expressed as units/mg protein and $p h$ GSHPx activity as munits/mg protein $100 \% c$ GSHPx activity is $0 \cdot 064,0.048$ and 0.040 units $/ \mathrm{mg}$ protein in $1-, 4-$ and 11 -day-old rats. $100 \%$ ph GSHPx activity is $0.95,4.3$ and 4.0 munits $/ \mathrm{mg}$ protein in 1-, 4 - and 11 -day-old rats.

* $P<0 \cdot 05$, *** $P<0 \cdot 01$, **** $P<0 \cdot 001$ as compared with control (+Se+I) (ANOVA).

and combined selenium and iodine deficiency caused decreases in hepatic $c$ GSHPx activity to less than $5 \%$ of control $(+\mathrm{Se}+\mathrm{I})$ in adult rats and their offspring at 1,4 and 11 days old. Iodine deficiency had no effect on hepatic $c$ GSHPx activity in adult rats or their pups. Selenium deficiency decreased hepatic $p h$ GSHPx activity in adult, 11-day-, 4-dayand 1-day-old rats, regardless of the iodine status. Iodine deficiency alone caused decreases in hepatic phGSHPx activity in 1 - and 11-day-old rats but had no effect in adult and 4-day-old pups. Hepatic ID-I, $c$ GSHPx and phGSHPx mRNA levels reflected the enzyme activities in adult, 11-day- and 4-dayold rats (not shown). mRNA levels could not be determined in livers from 1-day-old animals because of sample degradation.

\section{Brain selenoenzyme activities and mRNA expression}

Whole brain ID-I activity was unchanged by selenium and iodine deficiencies in 11- and 4-day-old rats but was increased by combined selenium and iodine deficiency in 1-day-old animals (Fig. 2). ID-II activity was increased in both iodine-deficient groups in 11- and 4-day-old animals and was decreased by selenium deficiency in 11-day-old rats. Brain ID-II activity was less than $0.01 \mathrm{fmol}$ iodine released/min per $\mathrm{mg}$ protein in 1-day-old rats and thus could not be determined. Brain $c$ GSHPx activity and mRNA levels were decreased by selenium and iodine deficiencies in 1-day-old rats and in both selenium-deficient groups in 4-day-old rats (Table 3). Selenium deficiency decreased brain $c$ GSHPx activity in 11-day-old rats despite mRNA levels being increased by selenium and iodine deficiencies. Brain $p h \mathrm{GSHPx}$ activities were unchanged by selenium and/or iodine deficiencies in 1-, 4- and 11-day-old rats. Brain phGSHPx mRNA levels were increased by selenium deficiency in 1-day-old rats and in both selenium-deficient groups in 4and 11-day-old rats. Iodine deficiency decreased, did not affect and increased cerebral phGSHPx mRNA levels in 1-, 4- and 11-day-old rats respectively (Table 3 ).

\section{Brain BDNF and MBP expression}

Brain BDNF mRNA expression was decreased by selenium deficiency in 4- and 11-day-old rats (Fig. $3)$. Iodine deficiency caused an increase in BDNF mRNA levels in 11-day-old rats but had no effect on expression in brain of 4-day-old rats. Combined selenium and iodine deficiency decreased cerebral BDNF mRNA levels in 4-day-old rats but had no effect in 11-day-old rats. MBP mRNA was not detected in the brain of 4-day-old rats. In brains from 11-day-old rats, MBP expression was lower in combined selenium- and iodine-deficient pups (Fig. 4). 

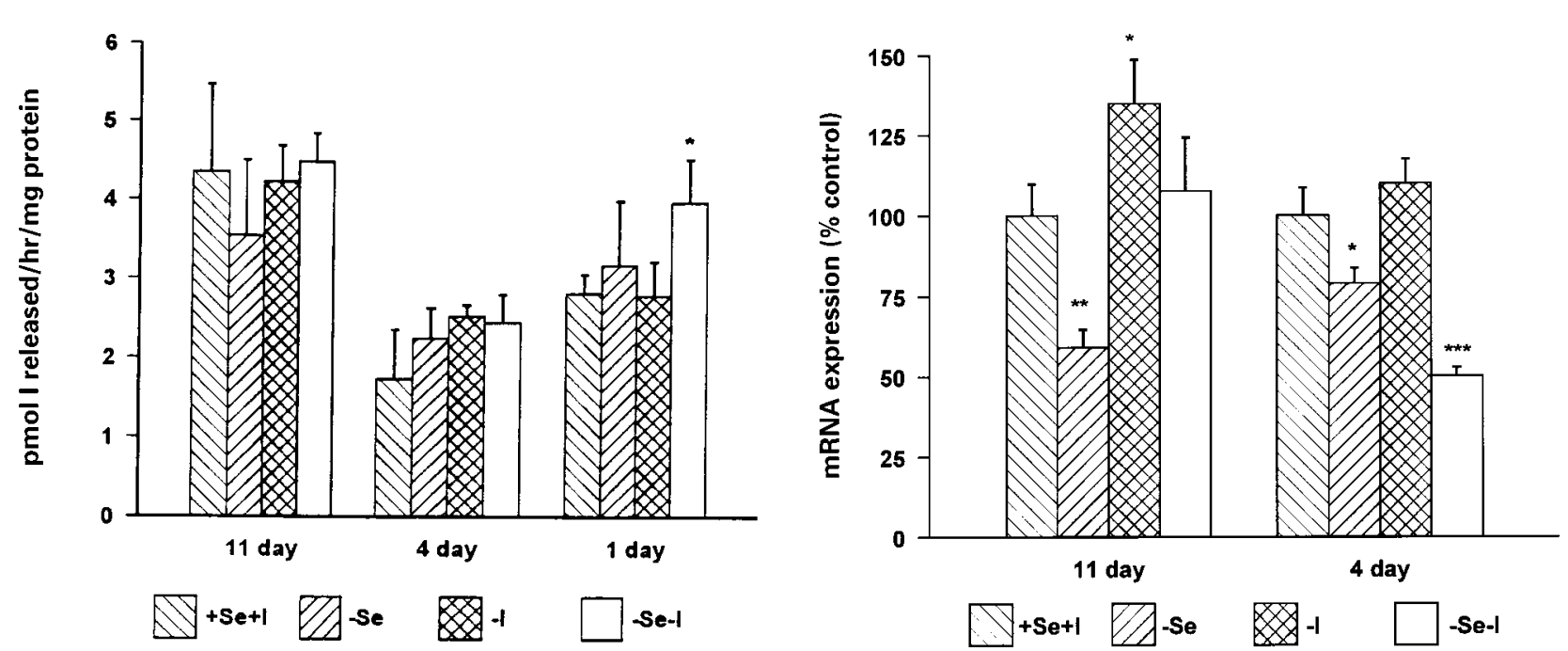

FIGURE 3. Effect of selenium and iodine deficiencies on cerebral BDNF mRNA expression in 4- and 11-day-old rats. mRNA was quantified using a Packard

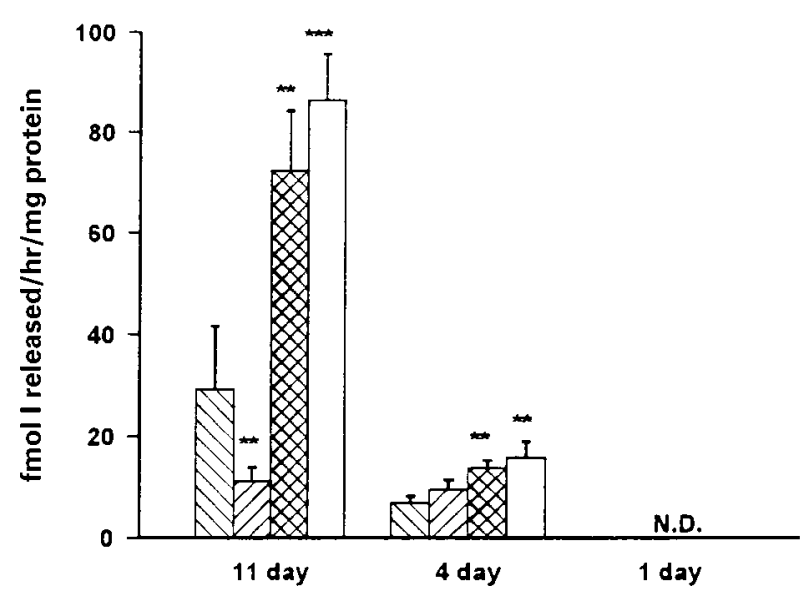

Instantimager and expressed as \% control $(+\mathrm{Se}+\mathrm{I})$ where control value $=100 \%$. Means \pm S.E.M. are shown $(n=5)$. $* P<0 \cdot 05, * * P<0 \cdot 01, * * * P<0 \cdot 001$ as compared with control (+Se+I) (ANOVA).

FIGURE 2. ID-I (top) and ID-II (bottom) activities in cerebrum from 1-, 4- and 11-day-old rats. ID-I activity is expressed as pmol iodine released/h per $\mathrm{mg}$ protein. ID-II activity is expressed as fmol iodine released/h per $\mathrm{mg}$ protein. N.D., not determined. Means \pm s.E.M. are shown $(n=5)$. $* P<0 \cdot 05$, ** $P<0 \cdot 01$, *** $P<0 \cdot 001$ as compared with control ( $+\mathrm{Se}+\mathrm{I})$ (ANOVA).

\section{DISCUSSION}

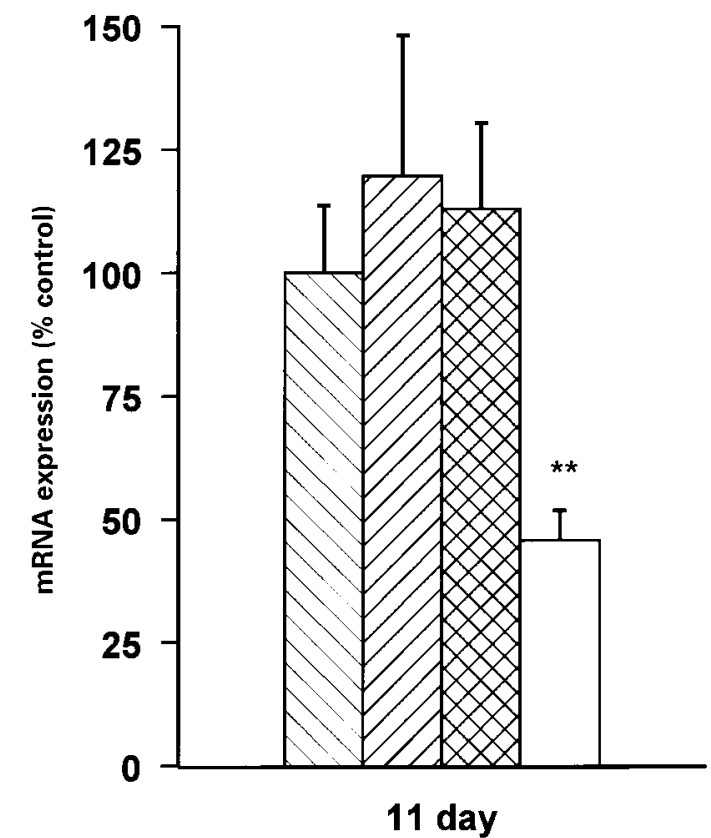

In adult rats and their 19-day-old pups, compensatory mechanisms exist to minimise thyroid hormone imbalance in selenium and iodine deficiencies (Mitchell et al. 1996, 1997). However, prolonged selenium and iodine deficiencies can have an adverse effect on brain biochemistry and development (Meinhold et al. 1993). This paper shows that such compensatory mechanisms exist, but are less efficient in 1-, 4- and 11-day-old selenium- and iodine-deficient rats. The diets used 
in the present studies caused iodine deficiency, as is evident from thyroid hypertrophy (7-fold increase in weight) and increased thyroidal ID-I activity in adult rats regardless of selenium status. In 11-day-old rats, thyroid gland weights increased $2 \cdot 5$-fold, and ID-I activity in the gland was increased by iodine deficiency alone, but was unchanged with a concurrent selenium deficiency and decreased by more than $50 \%$ in selenium deficiency alone (Fig. 1, Table 2). Thyroidal $c$ GSHPx activity, which in 19-day-old animals was unchanged in combined selenium and iodine deficiency (Mitchell et al. 1996), is decreased by more than half in 11-day-old rats, probably making the gland more susceptible to peroxidative damage (Table 2). Plasma TSH concentrations were increased in both iodine-deficient groups in adults and 11-day-old rats, but $\mathrm{T}_{4}$ concentrations were less than $20 \%$ of control levels, and plasma $\mathrm{T}_{3}$ concentrations were decreased. Hepatic ID-I, $c$ GSHPx and $p h$ GSHPx activities were decreased by selenium deficiency in adult rats and their pups at 1, 4 and 11 days, as the liver does not retain selenium as well as other organs (Mitchell et al. 1996). The above results are consistent with the compensatory mechanisms in selenium-deficient 1-, 4- and 11-day-old rats including loss of selenium from tissues such as liver and muscle.

In contrast with changes in liver selenoenzymes, brain ID-I activities in 4- and 11-day-old pups were unaffected by selenium or iodine deficiencies and were increased in 1-day-old pups in the concurrent selenium and iodine deficiency group (Fig. 2). Brain phGSHPx activities were not changed in 1-, 4- and 11-day-old rats probably because increased mRNA counteracted decreased selenium availability; however, $c \mathrm{GSHPx}$ activity was decreased despite increases in mRNA levels (Table 3). A similar preferential supply of selenium to phGSHPx over $c$ GSHPx occurs in different brain regions from adult rats and their 19-day-old pups (Mitchell et al. 1997). The brains from the younger rats were, however, too small to divide into the regions used in previous experiments (Mitchell et al. 1997). Brain ID-II activity was unaffected by selenium deficiency in 4-day-old animals but decreased by more than $50 \%$ in 11-day-old animals as compared with seleniumadequate controls. This would suggest that the older animals have become more seleniumdeficient despite the fact that the brain retains the micronutrient at the expense of other organs. Alternatively, there could be a form of ID-II which does not contain selenium but is specific to brain. Brain ID-II activity is also decreased in third-generation selenium-deficient adult rats; however, tissue $\mathrm{T}_{3}$ concentrations are not affected (Campos-Barros et al. 1997). Brain ID-II activity was increased $1 \cdot 5$-fold and 3 -fold in iodine deficiency in 4- and 11-day-old rats respectively regardless of selenium status (Fig. 2). In addition, brain ID-II activity increases substantially in iodine-deficient adults rats (Mitchell et al 1997), but, despite this, tissue $\mathrm{T}_{3}$ concentrations are decreased (Campos-Barros et al. 1997). Selenium deficiency caused 25 and $50 \%$ decreases in BDNF mRNA expression in 4- and 11-day-old rats respectively (Fig. 3). However, the differing effects of iodine deficiency on BDNF expression make these results very complicated to interpret. Although localised changes in thyroid hormone metabolism could have influenced BDNF expression, other selenoproteins such as thioredoxin reductase, which can indirectly modulate gene expression, may underlie the altered gene expression caused by selenium deficiency (Gladyshev et al. 1996, McLeod et al. 1997).

Myelination in the rat begins at around 10 days after birth and is delayed by hypothyroidism, as assessed by determination of MBP gene expression (Kristensson et al. 1986, Dussault \& Ruel 1987). In this experiment cerebral MBP mRNA abundance was lower in combined selenium and iodine deficiency than in the single micronutrient deficiencies or control animals. Thus a concurrent selenium deficiency may cause further delay in brain development in $\mathrm{T}_{4}$-deficient animals.

From birth, rats have compensatory mechanisms which can protect against a decrease in brain $T_{3}$ concentrations induced by selenium and iodine deficiencies. However, these mechanisms do not confer complete protection against the effects of selenium and/or iodine deficiencies, as is evident from decreases in MBP and BDNF mRNAs. The effects of the deficiencies on these mRNAs were different, which indicates that the mechanisms causing the changes are probably independent. Thus selenium may influence gene expression in ways that are not always mediated by thyroid hormone metabolism.

\section{ACKNOWLEDGEMENTS}

This work was supported by the Scottish Office Agriculture, Environment and Fisheries Department (SOAEFD). We wish to thank Ewan Wilkinson for his help with the analysis of thyroid hormone concentrations and Dr Mike Franklin of Biomathematics and Statistics Scotland (BioSS) for his help with the statistical analysis. 


\section{REFERENCES}

Arthur, JR, Nicol F \& Beckett GJ 1990a Hepatic iodothyronine deiodinase: the role of selenium. Biochemical Fournal 272 537-540.

Arthur JR, Nicol F, Rae PWH \& Beckett GJ $1990 b$ Effects of selenium deficiency on the thyroid gland and on plasma and pituitary thyrotrophin and growth hormone concentrations in the rat. Clinical Chemistry and Enzyme Communications $\mathbf{3}$ 209-214.

Beckett GJ, Beddows SE, Morrice PC, Nicol F \& Arthur JR 1987 Inhibition of hepatic deiodination of thyroxine is caused by selenium deficiency in rats. Biochemical Fournal 248 443-447.

Beckett GJ, Nicol F, Rae PWH, Beech SG, Guo Y \& Arthur JR 1993 Effects of combined iodine and selenium deficiency on thyroid hormone metabolism in rats. American Fournal of Clinical Nutrition (Suppl) 57 240S-243S.

Campos-Barros A, Meinhold H, Walzog B \& Behne D 1997 Effects of selenium and iodine deficiency on thyroid hormone concentrations in the central nervous system of the rat. European Fournal of Endocrinology 136 316-323.

Chomczynski P \& Sacchi N 1987 Single-step method of RNA isolation by acid guanidinium thiocyanide-phenolchloroform extraction. Analytical Biochemistry 162 156-159.

Contempre B, Dumont JE, Ngo B, Thilly CH, Diplock AT \& Vanderpas J 1991 Effect of selenium supplementation in hypothyroid subjects of an iodine and selenium deficient area: the possible danger of indiscriminate supplementation of iodine deficient subjects with selenium. Fournal of Clinical Endocrinology and Metabolism 73 213-215.

Contempre B, Duale NL, Dumont JE, Ngo B, Diplock AT \& Vanderpas J 1992 Effect of selenium supplementation on thyroid hormone metabolism in an iodine and selenium deficient population. Clinical Endocrinology 36 579-583.

Contempre B, Dumont JE, Denel JF \& Many MC 1995 Effects of selenium deficiency on thyroid necrosis, fibrosis and proliferation: a possible role in myxedematous cretinism. European Fournal of Endocrinology 133 99-109.

Croteau W, Whittemore SL, Schneider MJ \& St Germain DL 1995 Cloning and expression of a cDNA for a mammalian type II iodothyronine deiodinase. Fournal of Biological Chemistry 270 16569-16575.

Dussault JH \& Ruel J 1987 Thyroid hormones and brain development. Annual Reviews of Physiology 49 321-334.

Gladyshev VN, Jeang KT \& Stadtman TC 1996 Selenocysteine, identified as the penultimate C-terminal residue in human $\mathrm{T}$-cell thioredoxin reductase, corresponds to TGA in the human placental gene. Proceedings of the National Academy of Science of the USA 93 6146-6151.

Giordano T, Pan JB, Casuto D, Watanabe S \& Arneric SP 1992 Thyroid hormone regulation of NGF, NT-3 and BDNF RNA in the adult rat. Molecular Brain Research 16 239-245.

Kristensson K, Zeller NK, Dubois-Dalcq ME \& Lazzarini RA 1986 Expression of myelin basic protein gene in the developing rat brain as revealed by in situ hybridisation. Fournal of Histochemistry and Cytochemistry 34 467-473.

Leibrock J, Lottspeich F, Hohn A, Hofer M, Hengerer B, Masiakowski P, Thoenen H \& Barde Y-A 1989 Molecular cloning and expression of brain-derived neurotrophic factor. Nature 341 149-152.

McLeod R, Ellis EM, Arthur JR, Neal GE, Judah DJ, Manson MM \& Hayes JD 1997 Protection conferred by selenium deficiency against aflatoxin B1 in the rat is associated with the hepatic expression of an aldo-keto reductase and a glutathione S-transferase subunit that metabolise the mycotoxin. Cancer Research 57 4257-4266.

Meinhold H, Camposbarros A, Walzog B, Kohler R, Muller F \& Behne D 1993 Effects of selenium and iodine deficiency on type-I, type-II and type-III iodothyronine deiodinases and circulating thyroid hormones in the rat. Experimental and Clinical Endocrinology 101 87-93.

Mitchell JH, Nicol F, Beckett GJ \& Arthur JR 1996 Selenoenzyme expression in thyroid and liver of second generation selenium- and iodine-deficient rats. Fournal of Molecular Endocrinology 16 259-267.

Mitchell JH, Nicol F, Beckett GJ \& Arthur JR 1997 Selenium and iodine deficiencies: effects on brain and brown adipose tissue selenoenzyme activity and expression. Fournal of Endocrinology 155 255-263.

Nicol F, Lefranc H, Arthur JR \& Trayhurn P 1994 Characterisation and postnatal development of 5 '-deiodinase activity in goat perinatal fat. American Fournal of Physiology 267 R144-R149.

Perez-Castillo A, Bernal J, Ferreiro B \& Pans T 1985 The early ontogenesis of thyroid hormone receptor in the rat foetus. Endocrinology 117 2457-2461.

Weitzel F, Ursini F \& Wendel A 1990 Phospholipid hydroperoxide glutathione peroxidase in various mouse organs during selenium deficiency and repletion. Biochimica et Biophysica Acta 1036 88-94.

RECEIVED 20 June 1997 